An empirical test of diversity climate dimensionality and relative effects on employee of color outcomes.

By: Holly E. Buttner, Kevin B. Lowe and Lenora Billings-Harris

Buttner, E. H., Lowe, K. B., \& Billings-Harris, L., (2012) An empirical test of diversity climate dimensionality and relative effects on employee of color outcomes. Journal of Business Ethics. 110:247-258. DOI: $10.1007 / \mathrm{s} 10551-011-1179-0$

Made available courtesy of Springer Verlag. The original publication is available at www.springerlink.com.

***Reprinted with permission. No further reproduction is authorized without written permission from Springer Verlag. This version of the document is not the version of record. Figures and/or pictures may be missing from this format of the document. $* * *$

\begin{abstract}
:
This study examined the relative effect of diversity climate dimensions captured by two measures: Mor Barak et al.'s (Journal of Applied Behavioral Science, 34:82-104, 1998) diversity climate scale and Chrobot-Mason's (Journal of Managerial Psychology 18:22-45, 2003) diversity promise fulfillment scale on professional employee of color outcomes: organizational commitment (OC) and turnover intentions. We hypothesized that the two scales would measure different aspects of diversity climate. We further hypothesized that the different climate dimensions would interactively affect the employee of color outcomes. Third, we predicted that diversity climate would mediate between diversity promise fulfillment and employee of color outcomes. Finally, we hypothesized that organizational commitment would mediate the interactive effect of diversity climate dimensions on turnover intentions. Results indicated that the diversity scales each predicted unique variance in employee outcomes and that the climate dimensions interactively influenced professional of color organizational commitment and turnover intentions. We also found that the diversity climate dimension, as measured by the Mor Barak scale, mediated between diversity promise fulfillment and the outcomes. Finally, we found complete mediated moderation between the interaction of the two climate measures and turnover intentions by organizational commitment. Implications are discussed.
\end{abstract}

Keywords: diversity climate | employees of color | moderated mediation | organizational commitment | turnover intentions | management | business ethics

Article:

Abbreviations

DC Diversity climate as measured by the Mor Barak et al. (1998) scale

DP Diversity promises scale as measured by the Chrobot-Mason (2003) scale 
OC Organizational commitment

TI Turnover intention

Prior to the 1960's, the nascent literature on U.S. workforce diversity had a tendency to dare organizations to care about the treatment of under-represented groups. The literature shifted following the landmark U.S. civil rights legislation of the mid-1960's, to a focus on how to comply with legal guidelines for reducing discriminatory practices (e.g., disparate impact). More recently, the diversity literature has argued the business case for caring about workforce diversity. A major tenet of the business case is that the U.S. populace, where $42 \%$ of the population will be minority Americans by 2025 (U.S. Census Bureau 2008) and 53\% by 2050, is becoming increasingly ethnically diverse. Almost $90 \%$ of the population growth in coming decades will be comprised of people of color (Irwin 2004). Escalating work force diversity, in combination with the ongoing globalization of business, is leading to an increasingly competitive labor marketplace.

This study examines the predictive value of two measures of perceived diversity climate on employee outcomes: organizational commitment (OC) and turnover intentions. While increasing workforce diversity is inevitable and thus the attendant need for increased inclusiveness seemingly obvious, increased diversity does not necessarily lead to greater organizational performance. Evidence about the impact of workforce diversity has been mixed. Some findings suggest positive effects (Gonzalez and DeNisi 2009; Richard 2000; Richard et al. 2004), while other findings suggest negative effects (Joshi and Roh 2009; Sacco and Schmidt 2005). Recent research suggests that to improve organizational performance and inclusiveness, organizational diversity climates must change as workforces become more diverse (McKay et al. 2007, 2008).

Evidence suggests leaders appreciate the need for attention to the organizational diversity climate. At the beginning of the twenty-first century, 75\% of Fortune 500 companies had cultural diversity programs (Kalev et al. 2006; Kimley 1997). Buttner et al. (2009) reported that organizational leader recognition of organizational cultural change as well as more specific diversity policies including recruitment of employees of color and provision of performancerelated feedback were associated with (higher) minority employment levels. However, many organizations struggle with the challenge of operationalizing the management of this diversity. Shurn-Hannah (2000) and Robinson and Dechant (1997) report that minority group member turnover is significantly higher than for majority-group colleagues. McKay and Avery (2005) have argued that the juxtaposition of attraction and (lack of) retention success can be explained by the disconnect between companies' development of effective recruiting strategies and their lesser success in altering their diversity climates. Yet little is known about how diversity strategies, espoused or enacted, contribute to building a compassionate climate that is effective at attracting and retaining minority employees (Chavez and Weisinger 2008). Thus, understanding what drives organizational affiliation and turnover among professionals of color, an under- 
represented group, is a particularly important issue for managers generally and for human resource professionals specifically.

The purposes of this study are twofold: first, we examine two dimensions of diversity climate: (1) perceived fairness in employment decisions with respect to the ethnicity of employees, and (2) fulfillment of diversity promises to employees of color. Second, we explore the effects of these two climate dimensions on two employees of color outcomes, organizational commitment and turnover intentions, by proposing moderating and mediating effects for the diversity climate to employee outcome relationship. Prior to exploring diversity climate and its influence on employee outcomes in detail, we provide a discussion of psychological contract theory as the theoretical foundation for our research.

Psychological Contract Theory

The psychological contract is a construct that operationalizes the expected (anticipated) social exchange relationships between employees and their organizations. Rousseau (1989) and Morrison and Robinson (1997) define a psychological contract as the employee's belief about obligations or perceived promises between the employee and his/her employing organization (rather than between the employee and organizational agents). Psychological contracts are arrived at via a sense-making process, where employees integrate a constellation of explicit and implicit statements about the organization through the lens of their experience. This lens provides the vantage point through which employees develop expectations about and evaluate the fairness of work-related social exchanges.

Lack of fulfillment of the psychological contract on the part of the employer can lead to negative organizational outcomes. A contract breach is a cognition that the employee's organization has failed to meet its obligation to the employee as part of the psychological contract (Morrison and Robinson 1997). Robinson and Rousseau (1994) and Turnley and Feldman (1999) reported that psychological contract violations resulted in various employee outcomes including loss of trust, dissatisfaction and turnover. Other researchers have reported a similar pattern of results (Lo and Aryee 2003; Robinson and Morrison 2000; Robinson and Rousseau 1994; Tekleab et al. 2005). None of these studies examined the perceptions of employees of color; nor did they study the effect on employees when they perceived a breach of diversity climate promises.

Diversity Climate

One potentially important dimension of the psychological contract for minority employees pertains to expectations about fairness in the diversity climate of the employing organization. Diversity climate is defined as "employee behaviors and attitudes that are grounded in 
perceptions of the organizational context related to women and minorities." (Mor Barak et al. 1998, p. 83). Cox (1994) describes the context of diversity climate in terms of three levels: individual, inter-group and organizational factors. Cox's model of the diversity climate recognizes the interplay between the individual and the organizational situation in which that individual is embedded. Dimensions of the diversity climate include diversity in the employee work force, extent to which diverse input is valued in decision-making, hiring, and promoting employees regardless of their ethnicity, providing feedback fairly without consideration of an employee's ethnicity, provision of assignments based on skills and abilities of employees, and elimination of discrimination and bias (Cox 1994; Mor Barak et al. 1998). In their review of organizational and psychological climate, James et al. (2008) point out that psychological climate perceptions "assess the significance and meaning of work environments to individuals" (p. 8) in terms of how beneficial or detrimental the conditions are to the employee whereas organizational climate refers to commonly shared individual perceptions of the work environment. In this study, we focus on the perceptions held by individual employees, that is, their psychological climate perceptions.

Diversity climate, much like the effects of psychological climate on the expectations and career experiences of most employees, may be particularly salient for the expectations and career experiences of employees of color. Thomas and Wise (1999) reported that racial/ethnic minority group members were more sensitive to the diversity climate than were Caucasian men. Jeanquart-Barone (1996) found that African American subordinates reported lower levels of supervisory support, fewer developmental opportunities, lower procedural justice, less assimilation, and higher levels of discrimination when their supervisors were dissimilar (White). Hicks-Clarke and Iles (2000) found that diversity climate perceptions affect employees’ work outcomes including organizational commitment and job satisfaction. However, their study design grouped white and non-white participants' perceptions together and in contrast to the present study, they did not evaluate the effects of diversity climate on turnover intentions. Thus, the relationship between employees' of color psychological contracts with their employing organizations, as well as the impact of contract violations such as lack of fulfillment of organizational diversity promises on employee outcomes, are relatively unexplored but increasingly important research issues deserving empirical attention.

The research cited above pertaining to organizational climate suggests that our understanding of the interplay between diversity climate and employee outcomes could be enhanced by closer attention to the dimensionality of diversity climate, including employee of color perceptions of diversity policies and procedures. In contrast to considering dimensional aspects of diversity climate, much of the extant climate research uses global and non-specific measures of the psychological contract. For example Tekleab et al. (2005) identify the focus of the psychological contract construct as being on promises “made and kept” (p. 148), in essence a unidimensional measure. Our review of the literature suggests that an organization's diversity climate is likely to have facets that deserve closer empirical attention in research pertaining to psychological 
contract violation. Developing a finer grained understanding of diversity climate breach is likely to be important in understanding employee cognitive and behavioral reactions. More specifically, it may be important to examine facets of the diversity climate to determine which aspects have the greatest impact on employee of color outcomes. We now review the literature on facets of the diversity climate and literature that investigates the important role of diversity climate in organizations.

Assessment of Diversity Climate

Scholars have developed several assessments of diversity climate over the past two decades. In perhaps the first study of diversity dimensions, Kossek and Zonia (1993) operationalized diversity climate in terms of perceptions of organizational policies regarding allocation of resources as a function of employee gender and ethnicity in a university setting. A few years later, based on social identity and inter-group relations theories, Mor Barak et al. (1998) developed the Diversity Climate Perceptions Scale (DC) to assess fairness and inclusiveness with respect to diversity in organizations. Items in the organizational fairness subscale focus on issues pertaining to equality of treatment and to the fairness of various human resource and administrative policies and practices with respect to gender, ethnicity, religion, and age. The organizational inclusiveness subscale addresses such topics as organizational support of diversity networks, mentoring programs, and adequacy of diversity training programs.

Most recently, Chrobot-Mason (2003) developed the Diversity Promises scale (DP) to measure the extent to which an organization honors promises regarding the diversity climate for employees of color. This scale measures respondents' perceptions that organizational promises have been honored with respect to diverse workforce representation, elimination of bias, appreciation of input from minority group members and support for unique minority group issues. Chrobot-Mason also measured the extent to which the respondents valued each dimension of diversity climate and found that employees of color in one organization valued diversity promises as highly as more general organizational promises, such as high pay based on performance, job security, and support with personal problems. The properties of the scale developed by Chrobot-Mason appear to be quite strong; however, generalizability remains unknown because the participants were from one organization.

While Chrobot-Mason's Diversity Promise scale addresses broader, diversity climate issues, Mor Barak et al.'s scale asks about more proximal treatment by the employee's immediate superior. Though both Mor Barak et al.'s (1998) and Chrobot-Mason's (2003) scales measure aspects of diversity climate and are empirically related to employee outcomes (Buttner et al. 2010a, b; Caldwell et al. 2002; Chrobot-Mason 2003; Mor Barak et al. 1998; Stewart et al. 2011) and to organizational performance outcomes (McKay et al. 2008, 2009, 2011), no published study has determined whether the two scales measure similar or empirically distinct dimensions of 
diversity climate. If the two scales measure different aspects of the organizational diversity environment, administration of each scale should yield unique insight into the diversity climate. If the scales measure similar or overlapping outcomes, the literature findings generated from these two measures could be integrated with more confidence. However, no research to date has determined whether these constructs are conceptually distinct, that is, whether the scales measure independent or overlapping dimensions of diversity climate. This information may be helpful to researchers attempting to understand, manage, and modify a diversity climate that generates positive employee outcomes and to managers whose goal is to attract and retain high quality employees of color.

Hypotheses and Research Question

One purpose of this study is to determine whether Mor Barak et al.'s (1998) Diversity Climate Perceptions and Chrobot-Mason's (2003) Diversity Promises scales are empirically distinct. Thus, our first hypothesis is as follows:

\section{Hypothesis 1}

The (Mor Barak) diversity climate scale (and subscales) and the (Chrobot-Mason) Diversity Promises Scale measure different aspects of the organizational diversity environment.

While facets of diversity climate assessed by the two diversity climate scales have been shown to affect employee outcomes, no published research has examined their relative effect on organizational outcomes. Thus, the main purpose of this study is to determine which aspect of diversity climate, as measured by each scale, has relatively greater impact on employee outcomes: organizational commitment and turnover intentions. In doing so, we seek to answer our major research question which is: Does the Diversity Climate Perceptions Scale or the Diversity Promises Scale contribute more to explaining employee outcomes: organizational commitment and turnover intentions?

In this study, we make three additional substantive contributions to the literature. We explore in detail the role of diversity climate perceptions and diversity promise fulfillment on two important employee outcomes: organizational commitment and turnover intentions. First, we examine the interactive effect of diversity climate perceptions and diversity promise fulfillment on the two employee outcomes. Second, we test competing hypotheses concerning the mediating effect of diversity climate on the relationship between diversity promise fulfillment and employee outcomes. Finally, we extend the literature by examining the mediating role of organizational commitment on the interactive relationship between organizational diversity climate perceptions and diversity promise fulfillment on the outcome variable: turnover intentions. We now turn to a review of the relevant literature and propose five complementary hypotheses. 
Several scholars have examined the complex interplay between organizational diversity climate and organizational performance. Gonzalez and DeNisi (2009) in their study of the effect of diversity climate on organizational performance found that the impact of diversity climate is complex and dependent on the interplay of organizational factors. Therefore, they argued for a need to identify and examine moderators of the relationship between dimensions of diversity climate and organizational outcomes. Schulte et al. (2006) also proposed that it may be useful to examine multiple dimensions of psychological climate together. Such dimensions may reinforce each other, causing in essence, a moderating effect. Similarly, Ostroff et al. (2003) advocated for a configural approach involving simultaneously examining multiple aspects of climate to capture interrelationships between them. Such an approach may shed additional insight into the role of diversity climate on employee outcomes as evidence presented next suggests.

Several recent studies have examined the influence of various dimensions of the diversity climate on organizational outcomes using the diversity climate measures developed by Mor Barak et al. (1998) and Chrobot-Mason (2003). Using the Diversity Climate Perceptions Scale (DC), Mor Barack et al. (1998) found that Caucasian men perceived the organization as more fair than did Caucasian women or members of other racial/ethnic groups. Caucasian women and members of other racial/ethnic groups also saw more value in and felt more comfortable with diversity. McKay et al. (2007) used an abbreviated version of Mor Barak et al.'s (1998) DC measure to examine the diversity climate perceptions among managerial employees in a large U.S. retail organization. They found that a positive diversity climate was associated with higher organizational commitment and with lower turnover intentions, particularly for Black managers. Using a measure of diversity climate that included items which overlap with Mor Barak et al.'s (1998) organizational fairness subscale, McKay et al. (2008) reported that a supportive diversity climate was associated with higher sales performance at the U.S. retail organization.

Chrobot-Mason (2003), using the Diversity Promises Scale (DP) as the independent variable, found that while employees of color valued diversity promises as highly as general organizational promises, they reported that, in their experience, diversity promises were less likely to be met. Chrobot-Mason found that when employees of color reported that diversity promises had not been fulfilled, there were negative employment outcomes including lower organizational commitment, job satisfaction and higher levels of cynicism. In a follow-up study, examining the effect of diversity promise fulfillment, Buttner et al. (2010b) found that for their U.S. sample of professionals of color, perceptions of a breach in diversity promise fulfillment led to lower organizational commitment and higher turnover intentions.

In summary, both the Mor Barak and Chrobot-Mason measures of diversity climate were associated with employee outcomes. The Chrobot-Mason measure appears to capture more general aspects of diversity climate while Mor Barak et al.'s measure catalogs the effect of aspects of diversity climate closer to the focal employee. Thus, we expect that our findings for Hypothesis 1 will be that the DC scale and the DP scale measure different aspects of the 
diversity climate. From this expectation and based on the research cited above, we predict that these dimensions of diversity climate will interactively influence employee outcomes. When employees perceive that their organization has honored general diversity promises and the human resource decisions at the unit level have been made without regard to the employee's demographic characteristics, employees of color will be more committed and less likely to plan to leave their organization.

\section{$\mathrm{H} 2$}

Perceptions of diversity climate and diversity promise fulfillment will interact such that a positive diversity climate and strong diversity promise fulfillment will lead to higher organizational commitment.

H3

Perceptions of diversity climate and diversity promise fulfillment will interact such that a positive diversity climate and strong diversity promise fulfillment will lead to lower turnover intentions.

A competing alternative to the interaction argument can be made regarding the interplay of diversity promises at the organizational level and diversity climate as experienced at the unit level. Morrison and Robinson (1997) propose that various factors affect whether and how employees make attributions about psychological contract breaches. The salience of a dimension of the psychological contract affects whether a breach will be perceived. Contract aspects that are salient to an employee receive heightened attention and are more likely to be noticed. Morrison and Robinson also theorize that vigilance enacted by an employee influences the likelihood that the employee will perceive a breach. Similarly, since employment decisions made by an employee's supervisor are more proximal (salient) to the employee and may have greater impact on that employee's welfare than more distal promises made at the organizational level, the employee may be more likely to perceive and react to a perceived breach. Because treatment by the supervisor is more proximal to the employee, we might expect it to ameliorate the effects of promises broken at the organizational level.

As we noted earlier, several studies suggest that employees of color are sensitive to dimensions of the diversity climate, particularly employment decisions where race, gender and other demographic characteristics could come into play (Jeanquart-Barone 1996; Thomas and Wise 1999). In a study that examined the effect of behavioral integrity (the alignment between what a manager says and what s/he does in treatment of subordinates), Simons et al. (2007) reported that Black employees were more sensitive to managerial behavioral integrity than were members of any other racial group. Based on these findings, we propose that fulfillment of diversity promises would be salient to employees of color. 
Diversity climate, as operationalized by Mor Barak et al.'s (1998) scale appears more proximal and potentially has more substantive impact on the focal employee and thus may buffer, or mediate the effect of, more distal and general, diversity promises made at the organizational level. Thus, we predict that diversity climate may mediate the effect of diversity promises on important employee outcomes: organizational commitment and turnover intentions. From this line of reasoning two hypotheses follow:

\section{H4}

The relationship between diversity promise fulfillment and organizational commitment will be mediated by diversity climate.

\section{H5}

The relationship between diversity promise fulfillment and turnover intentions will be mediated by diversity climate.

A review of the literature indicates that organizational commitment and turnover, the two outcomes of particular interest in this research, are empirically related. Based on Fishbein and Ajzen's (1975) theory of planned behavior, Mobley et al. (1979) argued that individual, organizational and environmental variables influence the turnover process. Matthieu and Zajac (1990) found a strong association between organizational commitment and turnover intentions. Mobley et al. and Fishbein and Ajzen's theories suggest that cognitive and affective reactions ensue from experiences in the work environment, e.g., the diversity climate. These reactions become antecedents of attitudes and (intended) behavior, potentially including organizational commitment and turnover intentions.

Several studies have investigated the relationships between organizational commitment, and turnover intentions. In a study of public service employees, Albreacht (2006) found that affective organizational commitment mediated the relationship between trust in senior management, organizational support, and job satisfaction and outcome variables including turnover intentions. In a recent investigation of the relationship between diversity climate, organizational commitment, and turnover intentions, McKay et al. (2007) found that organizational commitment mediated the relationship between diversity climate perceptions and turnover intentions. organizational commitment in essence appears to act as a mediator between perceptions of a negative diversity climate and turnover intentions. McKay et al.'s sample included employees from one organization and used an abbreviated version of the Mor Barak diversity climate scale. We expand on McKay et al.'s findings by examining the interactive effect of diversity climate perceptions and diversity promise fulfillment on turnover intentions, mediated by organizational commitment across a number of organizations. We test this relationship with the following hypothesis: 
The moderated relationship of diversity climate perceptions and diversity promise fulfillment on turnover intentions will be mediated by organizational commitment.

Methods

Sample

The business school faculty professional labor market was sampled for this study. Faculty of color who were members of the PhD. Project, a U.S.-based network of professionals of color were solicited by email to participate in the study. Of the 662 faculty of color in the database with valid email addresses, 182 (27.5\%) filled out the survey. Twenty-eight surveys contained incomplete data for the variables of interest for this study and were deleted from this analysis. Thus, the number of surveys with complete data used for analysis was 154. Average age of the resultant sample was 45.1 years $(S D=9.1)$. Sixty-two percent of the sample were male and $38 \%$ were female. Sixty-four percent of the participants were African American, 21\% Hispanic, 4\% Asian American, 5\% Native American, 5\% were white non-Hispanic, and 1\% were in the "other" category. For position, 21\% indicated they were professors, $22 \%$ were associate professors, $52 \%$ were assistant professors, $2 \%$ were administrators, $2 \%$ were lecturers/instructors, and 1\% classified themselves as fitting into an "other" category. Forty-one percent indicated they were employed at doctoral-granting institutions, $13 \%$ were at nondoctoral-granting universities and $46 \%$ were at 4 -year colleges. Twelve percent were at historically black colleges or universities (HBCUs) and 88\% were at historically white institutions. Participants had been in their current position an average of 6.6 years (SD $=6.0$ ) when they completed the survey.

Among the respondents, $24 \%$ were in accounting, $10 \%$ in finance, $11 \%$ in information services, $35 \%$ in management and $20 \%$ were in marketing. In the $\mathrm{PhD}$ Project population of faculty of color, $28 \%$ were accountants, $9 \%$ were in finance, $13 \%$ in information services, $31 \%$ in management and $19 \%$ in marketing. Comparison of the sample to population characteristics indicates the sample was slightly over-represented in management and slightly under-represented in accounting.

Procedure

Approximately, 1 week before sending out the online survey, we emailed potential participants announcing the survey and indicating that the research was sanctioned by the PhD Project. We then sent the survey from a university server to the email address provided to us by the PhD. Project. We designed our administration strategy to verify the accuracy of the email addresses. 
Of the 685 email addresses of faculty at U.S. institutions of higher education on the list, 677 were valid addresses. Additionally, 15 individuals emailed to indicate they were not employed in the higher education industry and so we deleted them from the sample. Approximately, 2 weeks after the initial mailing, we sent a follow-up email and survey link to non-respondents again inviting them to complete the survey. The survey was completed online and data entered by participants was stored on a secure university server. The university's Institutional Review Board approved the study methodology and participation in the study was voluntary.

Measures

The Diversity Climate (DC) measure ( $\alpha=.89$ in this study; see Table 1 for individual items) is the ten-item scale developed by Mor Barak et al. (1998) which includes the 6 item organizational fairness subscale $(\alpha=.92)$ and the 4 item organizational inclusiveness subscale $(\alpha=.64)$. Diversity promise fulfillment (DP) was assessed with the five-item diversity promises subscale $(\alpha=.89$; see Table 1$)$ developed by Chrobot-Mason (2003). We measured organizational commitment with a seven-item scale from Mowday et al.'s (1979) organizational commitment questionnaire $(\alpha=.92)$. Sample items included: "I really care about the future of this university" and "I am proud to tell others that I am part of this university". The items were slightly altered to better fit the university setting. Turnover Intentions (TI) were measured with a two-item scale ( $\alpha$ $=.85$ ): "It is likely that I will leave my employment with this university within a year" and "I intend to keep working for the university for at least the next three years” (reverse-scored) (Cammann and Klesh (1979), as cited in Cook et al. 1981).

\begin{tabular}{|c|c|c|c|c|}
\hline \multirow{2}{*}{\multicolumn{2}{|c|}{ Item }} & \multicolumn{3}{|c|}{ Factor } \\
\hline & & 1 & 2 & 3 \\
\hline \multicolumn{5}{|c|}{ Diversity climate scale_-organizational fairness subscale } \\
\hline 1. & $\begin{array}{l}\text { I feel that I have been treated differently here because of my } \\
\text { race, sex, religion, or age }\end{array}$ & .42 & .57 & .02 \\
\hline 2. & $\begin{array}{l}\text { Dept. chairs have a track record of hiring and promoting } \\
\text { faculty members objectively regardless of their race, sex, } \\
\text { religion or age }\end{array}$ & .71 & .44 & .10 \\
\hline
\end{tabular}




\begin{tabular}{|c|c|c|c|c|}
\hline \multirow{2}{*}{ Iten } & & \multicolumn{3}{|c|}{ Factor } \\
\hline & & 1 & 2 & 3 \\
\hline 3. & $\begin{array}{l}\text { Dept. chairs here give feedback and evaluate faculty members } \\
\text { fairly, regardless of such factors as the faculty member's race, } \\
\text { sex, age, or social background }\end{array}$ & .84 & .38 & .18 \\
\hline 4. & $\begin{array}{l}\text { Dept. chairs here make promotion and tenure decisions fairly, } \\
\text { regardless of such factors as the faculty member's race, sex, } \\
\text { age, or social background }\end{array}$ & .85 & .36 & .14 \\
\hline 5. & $\begin{array}{l}\text { Dept. chairs interpret human resource policies (such as } \\
\text { sabbaticals) fairly for all faculty }\end{array}$ & .83 & .29 & .22 \\
\hline 6. & $\begin{array}{l}\text { Dept. chairs give assignments based on the skills and abilities } \\
\text { of faculty }\end{array}$ & .83 & .17 & .19 \\
\hline
\end{tabular}

\section{Diversity climate scale_organizational inclusion subscale}

\begin{tabular}{|c|c|c|c|c|}
\hline 7. & $\begin{array}{l}\text { Department chairs here encourage the formation of faculty } \\
\text { network support groups }\end{array}$ & .35 & .06 & .70 \\
\hline 8. & $\begin{array}{l}\text { There is a mentoring program in use here that identifies and } \\
\text { prepares all faculty of color and white female faculty for } \\
\text { promotion }\end{array}$ & .06 & .08 & .81 \\
\hline 9. & The "old boys network" is alive and well here & .34 & .43 & .20 \\
\hline 10. & $\begin{array}{l}\text { The university spends enough money and time on diversity } \\
\text { awareness and related training }\end{array}$ & .12 & .37 & .66 \\
\hline
\end{tabular}

\section{Diversity promises fulfillment scale}




\begin{tabular}{|c|c|c|c|c|}
\hline \multirow{2}{*}{ Item } & & \multicolumn{3}{|c|}{ Factor } \\
\hline & & 1 & 2 & 3 \\
\hline 11. & $\begin{array}{l}\text { The performance evaluation system at this university is a fair } \\
\text { one }\end{array}$ & .23 & .81 & .05 \\
\hline 12. & $\begin{array}{l}\text { I am satisfied with the way performance evaluations are done } \\
\text { at the university }\end{array}$ & .23 & .83 & .14 \\
\hline 13. & Different opinions, ideas, and perspectives are valued & .37 & .61 & .31 \\
\hline 14. & Racial bias and prejudice is eliminated & .30 & .76 & .13 \\
\hline 15. & $\begin{array}{l}\text { Support/understanding of unique issues is provided for } \\
\text { employees of minority groups }\end{array}$ & .21 & .75 & .23 \\
\hline
\end{tabular}

Items 1-6 constituted the diversity climate organizational fairness subscale. Items 7-10 constituted the organizational inclusiveness subscale and items 11-15 made up the diversity promise fulfillment scale. Eigenvalues are 7.48, 1.32 and 1.28 for factors 1, 2, and 3, respectively. Variances are 50, 9, and 9\% for factors 1, 2, and 3 respectively

Control Variables

Participant demographic variables of sex, age, ethnicity, and time in position were included in this study as control variables. Participant sex was coded as a dummy variable where $0=$ male and $1=$ female. Respondent ethnicity was recorded by respondents on the survey in six categories. Time in position was recorded by asking the respondents to enter the number of years that they had been in their current position.

Analysis

To address our research question and test our hypotheses, we undertook correlation analysis, factor analysis, regression, including hierarchical regression analyses of the study variables, and 
path analysis. To test Hypothesis 1, we conducted a confirmatory factor analysis using principal components with varimax rotation to determine whether the independent variables, diversity climate (with 2 subscales) and diversity promise fulfillment would load on 2 or 3 separate factors.

A concern in regression analysis, when interaction effects are tested is the possibility of multicollinearity that may occur because the interaction term may correlate with the variables from which it was derived. Accordingly, for the test of Hypotheses 2 and 3, we followed Aiken and West's (1991) recommendations to center the independent variables around zero by subtracting the mean from each value of the variables. We then determined whether interaction effects were indicated by calculating the simple slopes for one standard deviation above and below the mean for the predictor variables. To test for mediation for Hypotheses 4 and 5, we followed Baron and Kenny's (1986) three-condition analytical process. The first condition to show mediation is that the independent variable must relate to the dependent variable. The second requirement is that the independent variable must be significantly related to the mediator. The third condition for mediation is shown when both the independent variable and the mediator are included, the direct relationship between the independent and the dependent variable should be smaller (indicating partial mediation) or insignificant (indicating full mediation). Finally, we conducted Sobel's (1982) test for significance of the indirect effect of the independent variable on the dependent variable by way of the mediator. For the sixth hypothesis predicting moderated mediation, we conducted a path analysis.

Results

Hypothesis 1 and the research question focused on the empirical independence of perceptions of diversity climate (DC) and diversity promise fulfillment (DP). The results of the factor analysis showed that the two subscales of the diversity climate scale generally loaded on two factors, as shown in Table 1. The eigenvalue for Organizational Fairness subscale of the DC was 7.49 and explained $50 \%$ of the variance. The Organizational Inclusion subscale eigenvalue was 1.28 and explained an additional $8 \%$ of the variance. Items for Diversity Promises loaded cleanly on a third factor. The DP scale eigenvalue was 1.32 and explained an additional $9 \%$ of the variance. The three scales together explained $67 \%$ of the variance. Most items loaded consistently with the theory used in their development with two exceptions. Item 1 ("I feel I have been treated differently here because of my race, sex, religion, or age.”) and item 9 (“The 'old boys' network' is alive and well here.”) from the diversity climate scale cross-loaded on the DP scale. Thus hypothesis one, that diversity climate is multi-dimensional, was confirmed (Table 2).

Table 2

Correlations among the study variables 


\begin{tabular}{|c|c|c|c|c|c|c|c|c|c|c|}
\hline $\begin{array}{l}\text { Varia } \\
\text { ble }\end{array}$ & Mean & SD & (1) & (2) & (3) & (4) & (5) & (6) & (7) & \\
\hline (1) & Age & $\begin{array}{l}45 . \\
13\end{array}$ & $\begin{array}{l}9 . \\
14\end{array}$ & & & & & & & \\
\hline (2) & Sex & .38 & $\begin{array}{l}.4 \\
9\end{array}$ & $\begin{array}{l}-. \\
23\end{array}$ & & & & & & \\
\hline (3) & Ethnicity & $\begin{array}{l}1.9 \\
9\end{array}$ & $\begin{array}{l}1 . \\
04\end{array}$ & $\begin{array}{l}.0 \\
9\end{array}$ & $\begin{array}{l}.0 \\
1\end{array}$ & & & & & \\
\hline (4) & $\begin{array}{l}\text { Years in } \\
\text { position }\end{array}$ & $\begin{array}{l}6.5 \\
7\end{array}$ & $\begin{array}{l}5 . \\
99\end{array}$ & $\begin{array}{l}.4 \\
8\end{array}$ & $\begin{array}{l}-. \\
14\end{array}$ & $\begin{array}{l}-. \\
05\end{array}$ & & & & \\
\hline (5) & $\begin{array}{l}\text { Diversity } \\
\text { promise } \\
\text { fulfillmen } \\
\text { t }\end{array}$ & $\begin{array}{l}2.7 \\
7\end{array}$ & $\begin{array}{l}1 . \\
01\end{array}$ & $\begin{array}{l}-. \\
05\end{array}$ & $\begin{array}{l}-. \\
08\end{array}$ & $\begin{array}{l}-. \\
08\end{array}$ & $\begin{array}{l}- \\
06\end{array}$ & & & \\
\hline (6) & $\begin{array}{l}\text { Diversity } \\
\text { climate }\end{array}$ & $\begin{array}{l}2.9 \\
1\end{array}$ & $\begin{array}{l}.9 \\
3\end{array}$ & $\begin{array}{l}-. \\
09\end{array}$ & $\begin{array}{l}-. \\
17\end{array}$ & $\begin{array}{l}-. \\
11\end{array}$ & $\begin{array}{l}-. \\
08\end{array}$ & $\begin{array}{l}.7 \\
1\end{array}$ & & \\
\hline (7) & $\begin{array}{l}\text { Organizat } \\
\text { ional } \\
\text { commitm } \\
\text { ent }\end{array}$ & $\begin{array}{l}3.4 \\
2\end{array}$ & $\begin{array}{l}.9 \\
9\end{array}$ & $\begin{array}{l}-. \\
04\end{array}$ & $\begin{array}{l}-. \\
07\end{array}$ & $\begin{array}{l}-. \\
14\end{array}$ & $\begin{array}{l}-. \\
06\end{array}$ & $\begin{array}{l}.6 \\
3\end{array}$ & $\begin{array}{l}.6 \\
4\end{array}$ & \\
\hline (8) & $\begin{array}{l}\text { Turnover } \\
\text { intentions }\end{array}$ & $\begin{array}{l}2.4 \\
8\end{array}$ & $\begin{array}{l}1 . \\
36\end{array}$ & $\begin{array}{l}.0 \\
4\end{array}$ & $\begin{array}{l}.0 \\
5\end{array}$ & $\begin{array}{l}.0 \\
8\end{array}$ & $\begin{array}{l}-. \\
01\end{array}$ & $\begin{array}{l}- \\
46\end{array}$ & $\begin{array}{l}-. \\
43\end{array}$ & - \\
\hline
\end{tabular}

Correlations greater than .20 are significant at $\mathrm{p}<.05$; for sex, $0=$ male, $1=$ female; for ethnicity, 1 = African American, 2 = Hispanic, 3 = Asian American, 4 = Native American, 5 = White non-Hispanic, 6 = other; sample size was 154 
In summary, the DC and DP scales appear generally robust. The Organization Fairness subscale of the DC scale appears to measure fairness in human resource decisions. The Organization Inclusion subscale seems to capture organizational activities that promote inclusiveness. Finally, the Diversity Promises scale appears to summarize several dimensions of employee expectations about organizational diversity climate, supporting the first hypothesis.

The focal research question examined the relative influence of diversity climate perceptions versus diversity promise fulfillment on professional employee of color organizational commitment and turnover intentions. Results of the regression analysis with the two scales entered simultaneously indicated that diversity climate perceptions affected organizational commitment $(\mathrm{F}=106.02, \mathrm{p}<.001, \mathrm{r} 2=.41)$ and turnover intentions $(\mathrm{F}=34.80, \mathrm{p}<.0001, \mathrm{r} 2=$ .19), while diversity promise fulfillment influenced organizational commitment $(\mathrm{F}=98.56, \mathrm{p}<$ .0001 , r $2=.39)$ and turnover intentions ( $\mathrm{F}=41.01, \mathrm{p}<.0001, \mathrm{r} 2=.21)$. Results indicated that both scales had significant effects on the employee outcomes. In a post hoc analysis, we examined the effect of fairness and inclusiveness as measured by the diversity climate subscales on organizational commitment and turnover intentions through regression analysis. The results indicated that respondents' perceptions of fairness had a greater impact on organizational commitment $(\mathrm{F}=89.72$, $\mathrm{p}<.0001$, partial $\mathrm{r} 2=.39)$ than did perceptions of inclusiveness $(\mathrm{F}=$ 5.33, $\mathrm{p}<.05$, partial r $2=02$ ). For turnover intentions, only perceptions of organizational fairness had a significant effect $(\mathrm{F}=36.15, \mathrm{p}<.0001$, partial $\mathrm{r} 2=.21)$. The post hoc results suggest that when assessing diversity climate the professionals of color were more concerned about fair treatment than being included.

Having established empirically the multidimensionality of the diversity climate and the relative influence of diversity climate perceptions versus diversity promise fulfillment on professional employee of color organizational commitment and turnover intentions, Hypotheses 2 through 6 were tested to consider the interactive, moderated, and moderated mediation effects of these relationships. Hypothesis 2 predicted that DC and DP would interactively affect professional of color organizational commitment (OC) such that when employees perceived a favorable diversity climate and fulfillment of diversity promises, organizational commitment would be higher. To test the hypothesis, the demographic variables age, sex, ethnicity, and time in position, in the first step as controls and DC and DP in the second step were each regressed on organizational commitment. In a second set of regression analyses, an interaction term was added to the model to test for the interactive affect of DC and DP on organizational commitment. The demographic variables failed to affect organizational commitment. Hierarchical regression results indicated that, after controlling for demographic influences, DC $(\mathrm{F}=97.56, \mathrm{p}<.0001, \beta=$ $.43)$ and $\mathrm{DP}(\mathrm{F}=15.41, \mathrm{p}<.0001, \beta=.35)$ had main effects on organizational commitment. In the second set of analyses, DC and DP interactively influenced organizational commitment $(\mathrm{F}=$ 7.31, $\mathrm{p}<.01, \beta=-.17$ ), thus supporting the second hypothesis, as shown in Fig. 1 . To further investigate this interaction effect, we followed Aiken and West's (1991) procedure for determining the significance of the simple slopes. The simple slope analysis for one standard 
deviation above the mean $(\mathrm{t}=2.18, \mathrm{p}<.05)$, on the mean $(\mathrm{t}=4.50, \mathrm{p}<.01)$ and one standard deviation below the mean diversity promise fulfillment $(\mathrm{t}=3.04, \mathrm{p}<.01)$ was significant and in the predicted direction. Professionals of color who perceived high diversity promise fulfillment and a favorable diversity climate reported the strongest organizational commitment. Conversely, employees who perceived that diversity promises had lowest fulfillment and that the climate was unfavorable reported the lowest commitment to their organizations, thus supporting Hypothesis 2.

\section{*Figure 1 is omitted from this formatted document.*}

The third hypothesis predicted that DC and DP would interactively affect professional of color turnover intentions, such that when employees perceived a favorable diversity climate and fulfillment of diversity promises, turnover intentions (TI) will be lower. We used an analytical process similar to that for the second hypothesis. The demographic variables failed to affect TI. After controlling for the demographic variables, DC $(F=4.30, p<.05, \beta=-.33)$ and DP $(F=36.70 p<.0001, \beta=-.62)$ each influenced turnover intentions. DC and DP interactively affected TI $(F=6.40, p<.05, \beta=.26)$, in support of H3. To further investigate this interaction effect, we again followed Aiken and West's (1991) simple slope analysis. The simple slope analysis for low $(t=-3.13, p<.01)$ diversity promise fulfillment was significant and in the predicted direction. Professionals of color who perceived the lowest diversity promise fulfillment as well as an unfavorable diversity climate reported the highest turnover intentions, supporting Hypothesis 3, as shown in Fig. 2.

\section{*Figure 2 is omitted from this formatted document.*}

The fourth hypothesis predicted that (more proximal) diversity climate (DC) would mediate the relationship between (more distal) diversity promise fulfillment (DP) and organizational commitment (OC). Following Baron and Kenny (1986), we tested this hypothesis by running a series of regression analyses to test for mediation. The first condition was met; DP significantly predicted organizational commitment $(F=98.56, p<.001, \beta=.62)$. The second step was also met; DP influenced DC ( $F=155.99, p<.001, \beta=.66)$. To test for the third condition for mediation, we ran a third regression in which we forced DC to enter first, followed by DP. For organizational commitment, the overall $F$ was significant $(F=66.99, p<.001)$, but smaller due to the mediating effect of DC. Finally the Sobel (1982) test statistic $(z=8.02, p<.001)$ for the indirect effect of the independent variable (DP) on the dependent variable, organizational commitment, by way of the mediator, DC, was significant, suggesting that DC partially mediated the relationship between DP and organizational commitment and supporting Hypothesis 4.

The fifth hypothesis predicted that DC would mediate the relationship between DP and turnover intentions (TI). For turnover intentions as hypothesized by H5, the first condition was met; DP influenced TI $(F=41.01, p<.001)$. The second condition for TI was met; DP influenced DC $(F=155.99, p<.001)$. In the test for the third condition, the overall $F$ was significant 
$(F=23.09, p<.001)$ and DP significantly influenced TI $(F=9.45, p<.01)$, after controlling for the effect of DC. The Sobel (1982) test was significant as well $(z=5.36, P<.001)$, thus supporting Hypothesis 5. In summary, Hypotheses 4 and 5 that DC partially mediated the relationship between DP and organizational commitment and TI was supported for both dependent variables.

The sixth hypothesis proposed a mediated moderation relationship; that is, organizational commitment would mediate the relationship between the diversity climate by diversity promise fulfillment interaction (DC $\times$ DP) and turnover intentions. For hypothesis 6 , we first tested a fully specified model (no degrees of freedom) which included a path for a direct effect of the diversity climate perceptions (DC) and diversity promise fulfillment (DP) interaction (DC $\times$ DP) term on turnover intentions (TI) and an indirect path where organizational commitment (OC) mediated the path from DC $\times$ DP to TI. With all paths specified, the direct path was not significant while the path from the interaction term to the mediator (path coefficient $=.64, p<.01$ ) and the path from the mediator $(\mathrm{OC})$ to the TI were both significant (path coefficient $=-.57, p<.01$ ).

We then tested the same model by removing the path of the direct effects of the DC $\times$ DP interaction term on TI. The change in Chi-square was not significant $\left(\Delta \chi^{2}<4.0\right)$ confirming that a fully mediated model was supported. In the fully mediated model, the path coefficients were $.64,(p<.01)$ from DC $\times$ DP to organizational commitment and $-.62,(p<.01)$ from organizational commitment to turnover intentions with the fully mediated model explaining $38 \%$ of the variance. Thus, the results indicate that the diversity climate by diversity promise fulfillment interaction has only an indirect effect on turnover intentions by way of organizational commitment, in support of Hypothesis 6.

Discussion

The results of this study provide clear answers to our research question and hypotheses. The two predominant measures of diversity climate do assess different dimensions of perceived diversity climate and each dimension explains a significant amount of variance in each of the employee outcomes, organizational commitment and turnover intentions. We believe these findings have utility for practitioners seeking to respond to increasing workforce diversity where organizations are devoting more time, attention and money to diversity management. Many organizations use metrics including diversity scorecards to help guide and measure their progress regarding their evolving diversity and inclusion initiatives and goals in efforts to recruit and retain employees of color (Anderson and Billings-Harris 2010). Yet organizations have relatively few measures for understanding how diversity climate affects these outcomes. Future research could investigate the strategies organizations employ to engage employees of color for retention purposes. 
On a broader level, use of the two scales may help diversity professionals determine the effectiveness of efforts to improve the climate for diversity within work units. Our findings that the diversity climate perceptions scale by Mor Barak and colleagues and the diversity promise fulfillment scale by Chrobot-Mason appear to assess different facets of perceived diversity climate in an organizational setting should be useful to practitioners in identifying diversity outcome antecedents and to scholars in understanding the utility of these measures in future research. The diversity climate perceptions scale focuses on human resource decisions at the departmental level while the diversity promise fulfillment scale appears to capture expectations about diversity promises and their fulfillment at the organizational level. Assessment of perceived diversity climate by employing both scales may enhance understanding of the effects of perceptions about the diversity climate as each measure explains unique variance in employee outcomes. Future research could examine the main and interactive effects of the dimensions of perceived diversity climate captured by the two scales on other employee outcomes such as job satisfaction, psychological contract violation and actual turnover.

For scholars, the results of the hypotheses tested in the present study provide a finer grain analysis of how perceived diversity climate perceptions mediate the relationship between (more general and more distal) organizational diversity promises and employee outcomes:

organizational commitment and turnover intentions. These findings suggest that paying attention to the more proximal aspects of perceptions about the diversity climate and those human resource decisions which directly affect employees of color, such as fair treatment in hiring, promotion, feedback and performance evaluation are more important than diversity promises made at the organizational level. Enhancing unit level managers' awareness about the importance of fair and unbiased treatment as well as fostering employee awareness about how decisions are made may be particularly relevant. Our past research (Buttner et al. 2010b) suggests that employee perceptions of procedural justice play a mediating role in the relationship between diversity climate and organizational commitment. Future investigations could examine the effect of dimensions of diversity climate on other important organizational outcomes including employee trust in management and perceived organizational support.

The findings provide additional support, albeit with turnover intentions rather than actual turnover data, for Mobley et al.’s (1979) model of the individual-level voluntary turnover process. Organizational commitment, in this study mediated between perceived diversity climate, as measured by the interaction of the two climate dimensions and turnover intentions. Our results add to the growing body of literature investigating the relationships between perceptions about climate dimensions and organizational commitment and the mediating role of OC and turnover intentions. Diversity climate appears to be another aspect of psychological climate that affects outcomes for professional employees of color. Future research could determine whether organizational commitment mediates between the interaction of the two climate dimensions and actual turnover. 
There are several additional opportunities for future research to improve or extend the present study. Participants in this study were professionals who came from one industry, so the generalizability of the findings to other industries or to non-professional employees of color is unclear. Future research could examine the generalizability of the present findings by examining the effects of diversity climate and diversity promise fulfillment on the organizational commitment of other professionals, such as lawyers and accountants, as well as white professionals. A second limitation pertains to possible same source bias. However, concerns that these findings are a result of same source bias are reduced by the strong significance of the relationships found herein, by the evidence that the relationships are consistent with prior theorizing and empirical results, and by recent methodological research which suggests that concerns about same source bias have been overstated in the organizational literature (Spector 2006).

While we had representation of African American, Hispanic, Native American and Asian American professionals in our sample, the number of participants in the latter two categories was relatively low. Research assessing possible differences in attitudes among ethnic groups has been limited and could be a fruitful area for future investigation. As the U.S. work force becomes increasingly diverse, knowledge about the unique concerns of different ethnic groups, if any, will facilitate effective recruitment and retention strategies.

\section{References}

Aiken, L. S., \& West, S. G. (1991). Multiple regression: Testing and interpreting interactions. Newbury Park, CA: Sage.

Albreacht, S. (2006). Predictors of employee extra-role performance and turnover intentions in the public sector: An integrated model. International Journal of Human Resources Development and Management, 6, 263-278.

Anderson, R., \& Billings-Harris, L. (2010). Trailblazers: How top business leaders are accelerating results through inclusion and diversity. Hoboken, NJ: Wiley.

Baron, R. M., \& Kenny, D. A. (1986). The moderator-mediator variable distinction in social psychology research: Conceptual, strategic, and statistical considerations. Journal of Personality and Social Psychology, 51, 1173-1182.

Buttner, E. H., Lowe, K. B., \& Billings-Harris, L. (2009). The challenge of increasing minoritygroup professional representation in the United States: Intriguing findings. International Journal of Human Resource Management, 20, 771-789.

Buttner, E. H., Lowe, K. B., \& Billings-Harris, L. (2010a). The impact of diversity promise fulfillment on employee of color outcomes in the U S.Journal of Business Ethics, 91, 501-518. 
Buttner, E. H., Lowe, K. B., \& Billings-Harris, L. (2010b). Diversity climate impact on employee of color outcomes: Does justice matter? Career Development International, 15(3), 239-258.

Caldwell, Q. S., Mack, D., Johnson, C. D., \& Biderman, M. D. (2002). Value for diversity as a moderator of organizational relationships. Poster presented at the 17th Annual Meeting of the Society for Industrial and Organizational Psychology, Toronto, Canada.

Cammann, C., Fichman, M., Jenkins, D., \& Klesh, J. (1979). The michigan organizational assessment questionnaire. Unpublished manuscript, University of Michigan, Ann Arbor.

Chavez, I. C., \& Weisinger, J. Y. (2008). Beyond diversity training: A social infusion for cultural inclusion. Human Resource Management, 47(2), 331-350.

Chrobot-Mason, D. L. (2003). Keeping the promise: Psychological contract violations for minority employees. Journal of Managerial Psychology, 18, 22-45.

Cook, S. D., Hepworth, S, J., Wall, T. D., \& Warr, S, J. (1981). The experience of work: A compendium and review of 249 measures and their uses. New York: Academic Press.

Cox, T. (1994). Cultural diversity in organizations: Theory, research, and practice. San Francisco, CA: Berrett-Koehler Publishers, Inc.

Fishbein, M., \& Ajzen, I. (1975). Beliefs, attitude, intentions and behavior. Reading, MA: Addison Wesley.

Gonzalez, J. A., \& DeNisi, A. S. (2009). Cross-level effects of demography and diversity climate on organizational attachment and firm effectiveness.Journal of Organizational Behavior, 30, 2140.

Hicks-Clarke, D., \& Iles, P. (2000). Climate for diversity and its effects on career and organisational attitudes and perceptions. Personnel Review, 29, 324-345.

Irwin, N., I. I. (2004). America’s increasing diversity. Futurist, 38(2), 21.

James, L. R., Choi, C. C., Ko, C.-H., McNeil, P. K., Minton, M. K., Wright, M. A., et al. (2008). Organizational and psychological climate: A review of theory and research. European Journal of Work and Organizational Psychology, 17(1), 5-32.

Jeanquart-Barone, S. (1996). Implications of racial diversity in the supervisor-subordinate relationship. Journal of Applied Social Psychology, 26, 935-944.

Joshi, A., \& Roh, H. (2009). The role of context in work team diversity research: A metaanalytic review. Academy of Management Journal, 52, 599-627. 
Kalev, A., Dobbin, F., \& Kelly, E. (2006). Best practices or best guesses? Assessing the efficacy of corporate affirmative action and diversity policies. American Sociological Review, 71, 589617.

Kimley, A. (1997). Diversity programs: Coming of age. Black Enterprise Management, 4.

Kossek, E., \& Zonia, S. (1993). Assessing diversity climate: A field study of employer efforts to promote diversity. Journal of Organizational Behavior, 14, 61-82.

Lo, S., \& Aryee, S. (2003). Psychological contract breach in a Chinese context: An integrative approach. Journal of Management Studies, 40, 1005-1020.

Matthieu, J. E., \& Zajac, D. M. (1990). A review and meta-analysis of the antecedents, correlates, and consequences of organizational commitment.Psychological Bulletin, 108, 171194.

McKay, P. F., \& Avery, D. R. (2005). Warning! Diversity recruitment could backfire. Journal of Management Inquiry, 14, 330-336.

McKay, P. F., Avery, D. R., Tonidandel, S., Morris, M. A., Hernandez, M., \& Hebl, M. (2007). Racial differences in employee retention: Are diversity climate perceptions the key? Personnel Psychology, 60, 35-62.

McKay, P. F., Avery, D. R., \& Morris, M. A. (2008). Mean racial-ethnic differences in employee sales performance: The moderating role of diversity climate. Personnel Psychology, 61, 349374.

McKay, P. F., Avery, D. R., \& Morris, M. A. (2009). A tale of two climates: Diversity climate for subordinates' and managers’ perspectives and their role in store unit sales performance. Personnel Psychology, 62, 767-791.

McKay, P. F., Avery, D. R., Liao, H., \& Morris, M. (2011). Does diversity climate lead to customer satisfaction? It depends on the service climate and business unit demography. Organizational Science, 22, 788-803.

Mobley, W. H., Griffeth, R., Hand, H., \& Meglino, B. (1979). Review and conceptual analysis of the employee turnover process. Psychological Bulletin, 86, 493-522.

Mor Barak, M. E., Cherin, D. A., \& Berkman, S. (1998). Organizational and personal dimensions in diversity climate. Journal of Applied Behavioral Science, 34, 82-104.

Morrison, E., \& Robinson, S. (1997). When employees feel betrayed: A model of how psychological contract violation develops. Academy of Management Review, 22, 226-256. 
Mowday, R. T., Porter, L. M., \& Steers, R. M. (1979). The measurement of organizational commitment. Journal of Vocational Behavior, 14, 224-247.

Ostroff, C., Kinicki, A. J., \& Tamkins, M. M. (2003). Organizational culture and climate. In W. C. Borman \& D. R. Ilgen (Eds.), Handbook of psychology: Industrial and organizational psychology (Vol. 12, pp. 565-593). New York: Wiley.

Richard, O. (2000). Racial diversity business strategy, and firm performance. Academy of Management Journal, 43, 164-177.

Richard, O., Barnett, T., Dwyer, S., \& Chadwick, K. (2004). Cultural diversity in management, firm performance, and the moderating role of entrepreneurial dimensions. Academy of Management Journal, 47, 255-266.

Robinson, G., \& Dechant, K. (1997). Building a business case for diversity. Academy of Management Executive, 11(3), 21-31.

Robinson, E., \& Morrison, E. W. (2000). The development of psychological contract breach and violation: A longitudinal study. Journal of Organizational Behavior, 21, 525-547.

Robinson, S., \& Rousseau, D. M. (1994). Violating the psychological contract: Not the exception but the norm. Journal of Organizational Behavior,15, 245-259.

Rousseau, D. M. (1989). Psychological and implied contracts in organizations. Employee Responsibilities and Rights Journal, 2, 131-139.

Sacco, J. M., \& Schmidt, N. (2005). A dynamic multilevel model of demographic diversity and misfit effects. Journal of Applied Psychology, 90, 203-231.

Schulte, M., Ostroff, C., \& Kinicki, A. (2006). Organizational climate systems and psychological climate perceptions: A cross-level study of climate-satisfaction relationships. Journal of Occupational and Organizational Psychology, 79, 645-671.

Shurn-Hannah, P. (2000). Solving the minority retention mystery. Human Resource Professional, 13, 22-27.

Simons, T., Friedman, R., Liu, L. A., \& McLean Parks, J. (2007). Racial differences in sensitivity to behavioral integrity: Attitudinal consequences, in-group effects and "trickle down" among Black and Non-Black employees. Journal of Applied Psychology, 92, 650-665.

Sobel, M. E. (1982). Asymptotic confidence intervals for indirect effects in structural equation models. In S. Leinhart (Ed.), Sociological methodology(pp. 290-312). Jossey-Bass: San Francisco. 
Spector, P. E. (2006). Method variance in organizational research: Truth or urban legend? Organizational Research Methods, 9, 221-232.

Stewart, R., Volpone, S., Avery, D., \& McKay, P. (2011). You support diversity, but are you ethical? Examining the interactive effects of diversity and ethical climate perceptions on turnover intentions. Journal of Business Ethics, 100, 581-593.

Tekleab, A., Takeuchi, R., \& Taylor, M. S. (2005). Extending the chain of relationships among organizational justice, social exchange and employee reactions: The role of contract violations. Academy of Management Journal, 48, 146-157.

Thomas, K., \& Wise, P. (1999). Organizational attractiveness and individual differences: Are diverse applicants attracted by different factors? Journal of Business and Psychology, 13, 375390.

Turnley, W., \& Feldman, D. (1999). The impact of psychological contract violations on exit, voice, loyalty and neglect. Human Relations, 52, 895-922.

U.S. Census Bureau. (2008). National Population Projections. Calculations determined from Tables 13-20 athttp://www.census.gov/population/www/projections/summarytables.html. Accessed 7 Oct 2011. 